\title{
Partnering Strategies of Organizational Networks in Complex Environment of Disaster in the Centralized Political Context
}

\author{
Zhigang Tao (iD) and Haibo Zhang (iD \\ School of Government at Nanjing University, Nanjing, China \\ Correspondence should be addressed to Haibo Zhang; zhb@nju.edu.cn
}

Received 4 August 2020; Revised 14 November 2020; Accepted 22 November 2020; Published 1 December 2020

Academic Editor: Atila Bueno

Copyright (c) 2020 Zhigang Tao and Haibo Zhang. This is an open access article distributed under the Creative Commons Attribution License, which permits unrestricted use, distribution, and reproduction in any medium, provided the original work is properly cited.

\begin{abstract}
Organizational networks are a widely used approach to deal with the "wicked problems" of disasters. However, current studies are insufficient in examining what strategies organizations actually employ to select partners in a complex environment of disaster, particularly in the centralized administrative context. This case study uses exponential random graph models (ERGMs) to explore different partnering strategies that organizations used to form organizational networks in response to the Tianjin Port blast, a wellknown disaster in China. Results demonstrate that participating organizations prefer (a) the bonding structure strategy to form "reciprocity" and "transitive clustering," (b) the power concentration strategy to work with popular organizations, and (c) the homophily strategy to work with similar attribute organizations. However, contextual backgrounds influenced organizational attributes and strategies. This study discusses the implications of the findings and offers recommendations for enhancing collaboration among organizations.
\end{abstract}

\section{Introduction}

Public administrators increasingly use collaborative, networked forms of governance to address "wicked problems" such as disasters $[1,2]$. Extreme events can be natural or human-induced occurrences, and they are characterized by high salience, uncertainty, and impact. Greater complexity and more interconnected, and interdependent social systems contribute to the increased frequency and severity of extreme events [3-5]. Dealing with these extreme events requires multiple sectors and jurisdictions to operate simultaneously under high levels of uncertainty. Thus, the emergency response is a complex networked world where organizations with different sectoral and jurisdictional backgrounds to interact with and adapt to each other to collectively restore order from chaos [6].

While the reasons for creating organizational networks in disaster response is abound, the primary explanation is that networks offer less rigid and more flexible nonhierarchical structures $[7,8]$ that can fit the multifaceted, complex context of disasters $[6,9]$. In disaster response, networks provide organizations with the opportunity and benefit of shared resources and information and the capacity to adapt and adjust to changing environments.

Given the importance of interorganizational networks in disaster response, researching this aspect of emergency management can provide insights into the operation and process of disaster management [10]. An underexamined issue of the existing research is what strategies organizations actually employ to select partners in the complex context of disaster. It is not that previous studies have ignored partnering strategies of organizational networks in a complex environment of disasters, rather they have identified several partnering strategies of organizational networks in crisis communication [11-13], wildfire response [14, 15], and border management [16]. Most of the research was conducted in the context of the Western democratic systems. We still know little about what indicators do organizations look for to anticipate prospective partners' capacities and trustworthiness in disaster response in the centralized political context. This knowledge gap offers considerable opportunities for conducting disaster response network 
research. The context of each unique culture with its own set of problems may affect network formation. Explorations of new contexts could contribute to a better understanding of organizational networks overall [16].

In this study, we aim to respond to the knowledge gap by examining the network of partnerships among organizations in a well-known technical disaster, the Tianjin Port blast, in the context of the centralized administrative system of China. We develop several hypotheses about partnering strategies and test them with exponential random graph models (ERGMs). ERGMs support inferential analysis of highly interdependent data to explain and predict network formation [17]. The primary theoretical contribution of this study is the identification of partnering choice of organizational networks and examination of the pattern of collaborations in emergency response. Based on our research findings, we also propose policies and administrative implications for enhancing organizational networks to manage disasters in practice.

In the following section, we present an account of organizational networks and organizational partnering strategies. The third section presents the context of this study, the Tianjin Port blast. Next, we discuss the data and methods and offer a statistical network model to test the hypotheses. Subsequently, the study confirms the model results to uncover organizational partnering strategies in networks. In the last section, we summarize the findings and suggest policy and administrative strategies for strengthening collaborative relationships among organizations in the disaster response network in the context of China.

\section{Literature Review and Hypotheses}

This section presents an account of previous research on organizational networks and their application in the field of emergency management, and then develops several hypotheses.

\subsection{Organizational Networks}

2.1.1. Organizational Networks in Complex Environment. Disasters pose an extraordinary test for public administrators. These extreme events occur with increasing frequency in complex and interdependent environments and generate increasing costs in loss of lives, damage to infrastructure, property, and disruption of social and economic operations [18]. The dynamic context of disaster requires coordination of actions among multiple organizations, as well as the integration of multiple sectors and jurisdictions into a functioning system [19]. Similar views are voiced by Clarke and Chenoweth [20] and Comfort [21] who consider a system of interacting agencies and jurisdictions will be able to adapt more appropriately to internal and external in a given region as compared to separate and uncoordinated efforts by agencies acting independently to meet the same challenges. In a complex and turbulent environment, organizations frequently develop formal or informal relationships to search and exchange information [21], to identify emerging risks and anticipate the spread of risks [6], to develop a "common operating picture" [22], and to devise strategies for collective actions [19]. During this process of interactions, a new network or a stronger organizational network is created.

Organizational networks have been widely used in response to complex disaster events, which require the engagement of multiple stakeholders for effective results $[9,23]$. The term "network" is defined in many ways, but in its simplest term, it is a governance structure designed to achieve a common goal that a single organization could not achieve effectively on its own $[1,8]$. This concept is based on the idea that actors are interdependent and thus should work together to achieve a common goal [24, 25]. Multiple stakeholders, governments, private actors, and nonprofits engage in consensus-oriented decision-making [7] or collective action processes [26] to deal with wicked problems. As an alternative to, rather than a hybrid of, markets or hierarchies [27], networks more effectively address problems when they require adaptive, flexible approaches in the face of inconsistent information, uncertain conditions, and resources that span boundaries [28].

Traditional emergency management systems characterized by rigid boundaries, a top-down approach, and command-and-control mechanisms have proved less effective when dealing with extreme events [29, 30]. Building and sustaining disaster response networks are fundamental to current emergency management practices [31]. Researching this aspect of emergency management has been growing. Researchers have applied social network analysis to identify key actors [22, 32] and network structures [10] to evaluate the performance of emergency management networks $[33,34]$, to examine the model of crisis governance networks $[35,36]$, and to compare different types or stages of networks $[31,37]$.

Emergency management network research has also witnessed a shift to the microanalysis of the emergence of relationships among individual organizations. Recent analytical advancements, such as ERGMs, have allowed researchers to understand organizations' choice for establishing relationships with others. The mobilization of effective operation requires organizations to act quickly and effectively in response to urgent needs [18]. It is impractical, if not impossible, for an organization to maintain ties with all of the organizations in a network. Instead, it is more feasible for an organization to look for "indicators" to anticipate prospective partners' capacities and trustworthiness $[38,39]$. Bodin and colleagues' work on wildfire responder networks $[14,15]$ suggests that task dependencies and working with a third common actor are more likely to activate relationships between two actors. Hossain and colleagues' research on crisis communication networks $[11,13]$ stresses that relationships tend to form around a few central actors. Recent studies by Kim et al. [12] and Yeo [16] suggest that actors tend to build tight-knit relationships through bonding and clustering.

2.1.2. Organizational Response Network in China. The Severe Acute Respiratory Syndrome (SARS) crisis of 2003 was 
a "focusing event" that led to institutional changes in the emergency management system [40]. One of these changes was the enactment of the National Emergency Response Law in 2007, which outlines the emergency management system in China. According to the National Emergency Response Law, the emergency management system in China is designed as a combination of hierarchical command-andcontrol systems, on the one hand, and networks on the other.

Horizontally, at each jurisdictional level, disaster response is an interagency and intersectoral network. The National Emergency Response Law identifies the State Council as taking the lead role in managing catastrophic disasters and specifies the roles and responsibilities of various ministries and agencies based on the type of disaster [41]. National ministries and agencies facilitate coordination among supporting ministries or bureaus. Specialized interagency committees (headquarters) were established and responsible for making strategic decisions and coordinating actors in times of crisis. An emergency committee consists of representatives of public organizations, state-owned enterprises, and public institutions. In China, public institutions are organizations that charge fees for their provision of public services, whereas state-owned enterprises are in transition from public to private entrepreneurial organizations [42]. Provincial, municipal, and county-level governments have adopted a similar network structure. Each level of government has established an emergency management network consisting of public organizations, public institutions, and state-owned enterprises to improve collaboration among the participants. In disaster response, emergent members and typically nonprofit and private actors may also enter emergency management networks. Thus, at each level, emergency management is an interagency and intersector networked world.

Vertically, China's emergency response system has introduced a mechanism that matches the scale of the emergency with the appropriate level of jurisdiction. Emergencies and crises are categorized based on scale and intensity: I "catastrophic," II "severe," III "moderate," and IV "mild" [43]. The central (national), provincial, municipal, and county governments manage emergencies from most to least severe, respectively. The more severe the situation, the higher the jurisdictional level of government needed to supervise the response. As a disastrous situation evolves and deteriorates, the emergency response network expands, and higher levels of government become involved. Hence, a unified leadership and multiple jurisdictions of emergency management have been established, and power and responsibility are shared hierarchically among different levels of government.

There has been a considerable exploration of partnering strategies in organizational response networks. Most studies have been conducted in the context of Western democratic systems. However, the direction and significance of the same network antecedents might vary according to the political context. To improve generalizability, explorations of new contexts with a replicated research design could contribute to a better understanding of emergency management networks [16]. Such studies could help researchers to identify patterns of collaboration in a new context and help network administrators to devise practical strategies for enhancing the current benefits of organizational networks $[16,44]$. Thus, in this study, we examine organizational partnering strategies of the disaster response network in the centralized administrative context of China.

\subsection{Organizational Partnering Strategies and Hypotheses}

2.2.1. The Bonding Structure Strategy. The network literature has cited network structure as a determination of the establishment of relationships among individual organizations. Among all structures of a network, we examine "reciprocity" and "transitive clustered," which are associated with basic social bonding structures.

"Reciprocity," also known as mutual bonding, captures the propensity of organizations to establish a mutual tie with whom they had a one-way relationship during the disaster response. As shown in Figure 1, mutual relationships are established if Actor A creates a tie with Actor C and Actor C creates a tie with Actor A. Building reciprocal relationships may be the simplest and most straightforward strategy for collaborating with others [16]. It does not require actors to collect additional information. Rather it is simply to return ties to those with whom ties already exist. Through formulating reciprocal relationships, organizations can get timely information and feedback $[12,44]$. Formulating reciprocal ties also creates the "shadow of the future" by punishing the defection of actors and sustaining credible commitments between two actors [45-47]. Therefore, organizations involved in emergency response may formulate ties by simply returning resources or information to those from whom they have received the same.

Hypothesis 1. Within disaster response networks, organizations are likely to build reciprocal relationships.

"Transitive clustering," also known as social bonding, captures the tendency of organizations sharing ties with the same partners to form ties with each other [48]. As shown in Figure 1, the existence of a relationship between Actors A and $\mathrm{B}$ and a relationship between Actors $\mathrm{B}$ and $\mathrm{D}$ may encourage Actor A to reach out to Actor D. There are several reasons for organizations to form a transitive cluster. First, by forming more redundant communication ties, organizations may gain resources and support from the third actor, which can prove critical in adapting to a devastating situation and securing organizational survival [16]. Second, transitive clusters may enforce trust and commitment among actors and reduce the cost of control through overlapping information [46, 49]. An organization may assume the trustworthiness and commitment of the prospective partner by relying on previous experience with an existing partner or accepting a referral from a current partner. In a clustering structure, organizations can avoid the narrow pursuit of individual interests, enrich relationships through trust, and prompt cooperation and adaption to unexpected circumstances $[50,51]$. Finally, a tightly clustered network structure reduces the transaction costs of 


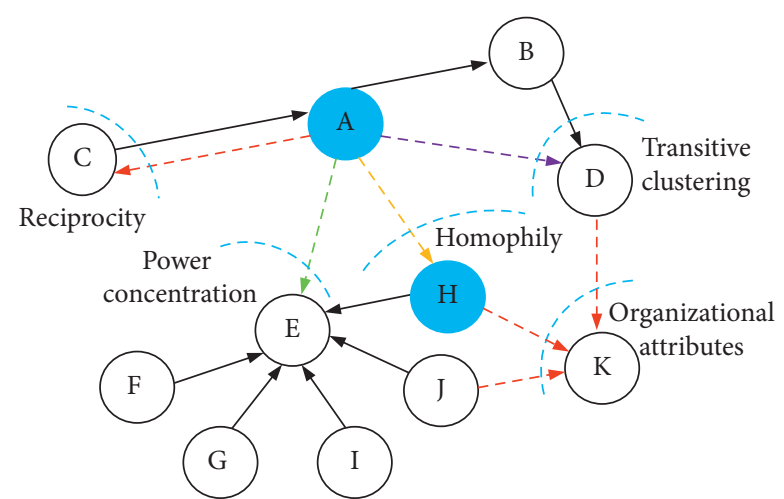

FIgURE 1: Strategies of partner selections. K represents public organizations or local organizations and blue represents organizations that have the same attribute (sector or jurisdiction).

enforcing and monitoring relational obligations because the actions taken, or not taken, by a locality are public $[45,52]$. Therefore, two organizations may forge a new transitive relationship when they share a common working partner.

Hypothesis 2. Within disaster response networks, organizations are likely to build transitive relationships with those sharing a common partner.

2.2.2. The Power Concentration Strategy. The power concentration strategy captures the tendency of organizations to establish relationships with a central organization that is disproportionately selected by many other actors in the domain $[45,47]$. In network analysis, the power concentration strategy is also called the preferential attachment effect that captures the tendency for popular organizations with more existing ties to gain more additional relationships over time (the richer get richer). As shown in Figure 1, Actor A may establish ties with Actor E, a popular organization that already has many relationships with others. Lee et al. [47] argued that in many situations, connecting with popular organizations can be beneficial in terms of a cost-benefit calculation and information and resource flow. Meanwhile, connecting with popular organizations can also lead to a situation where actors will benefit from adopting the most common approach to common problems and well-coordinated actions [48, 49]. In a turbulent environment, it is natural to use existing relationships as predictors of trustworthiness, leadership, skills, abilities, and capacity. Those who have many links with others are more able to respond than those with no links. Therefore, we claim that organizations are more likely to create collaborative ties with popular actors to secure useful information and well-coordinated collective actions.

Hypothesis 3. Within disaster response networks, organizations are more likely to build relationships with popular organizations.

2.2.3. The Homophily Strategy. The homophily strategy indicates that an organization has a strong preference for forging ties with another organization if they share similar attributes (i.e., culture, jurisdiction, and size). Organizational similarities secure the willingness and capability of maintaining mutual agreements [53], which are essential in minimizing the collaboration costs and risks that can derive from uncertainty among organizations $[49,54]$. Similarities among organizations also provide a common ground for defining problems and methods for dealing with problems $[50,55]$ and for moderating tensions or conflicts when organizations negotiate issues and interests [16].

In the emergency management literature, studies explain that similarities develop common operating pictures among organizations and further reduce the risks and burdens of collaboration $[6,56]$. For example, public organizations may be unwilling to work with nonprofits in disaster response because they doubt the capacities and motivations of nonprofits. Therefore, this study hypothesizes that organizations within the same sectors have a strong preference for building collaborative relationships.

Hypothesis 4. Within disaster response networks, organizations are more likely to build relationships with organizations that have similar sectoral attributes.

Networks place less emphasis on traditional top-down authority mechanisms and instead stress the importance of lateral communications and collaborations. A recent study has proved that network participants build stronger intrajurisdictional relationships than interjurisdictional relationships [57]. We hypothesize that organizations with the same jurisdictional level have a strong preference to build relationships with each other.

Hypothesis 5. Within disaster response networks, organizations are more likely to build relationships with organizations that have similar jurisdictional attributes.

2.2.4. The Organizational Attribute Strategy. Studies identify that actors may also rely on organizational attributes, such as sectors or jurisdictional responsibilities when selecting their working partners [49]. This partner selection tendency depends on specific contextual conditions. In the disaster context, public organizations have legal responsibilities to protect their constituents from harm [18]. Organizations from other sectors may collaborate with public organizations for various reasons. In China, public institutions and state-owned enterprises are extensions of the government, and thus, they have closer collaborative relationships with public organizations in disaster response. Besides, China's overall institutional environment tends to restrict emergent organizations, mainly private actors and nonprofits, in disaster response. Most emergent organizations remain small-scale with limited financial and human resources and insufficient capacities [58]. For these organizations, collaborating with public organizations may enhance their legitimacy and social status and help them gain the resources and skills they need. We hypothesize that organizations are likely to build relationships with public organizations in disaster response. 
Hypothesis 6. Within disaster response networks, other sectoral organizations are likely to establish relationships with public organizations.

Lastly, jurisdictional levels may also affect the formation of network ties in disaster response. For example, local governments may refuse to collaborate with national/central governments when they are rival political parties [57]. Thus, organizations with different jurisdictional responsibilities may use mediators, who can understand and translate the different actors' perspectives at the macro- and microlevels [16]. Within the disaster response context, actors may prefer provincial organizations because they can bridge national and local organizations in sharing resources and information. In China's context, provincial organizations play important roles in disaster response. A recent study proved a clear shift toward internal coherence at the provincial level, indicating that both national and local organizations were more likely to collaborate with provincial organizations [18]. Thus, we hypothesize that organizations are likely to establish relationships with provincial organizations in disaster response.

Hypothesis 7. Within disaster response networks, other jurisdictional organizations are likely to establish relationships with provincial organizations.

\section{Case Context}

This study investigates the case of the organizational network that emerged in a well-known technical disaster, the Tianjin Port blast. The case of the Tianjin Port blast is appropriate for examining the characteristics of a technical disaster response because it is a typical technical disaster in China and its response involved a broad range of organizations with different sectoral and jurisdictional backgrounds.

On August 12, 2015, at 11:34 pm., two blasts occurred at the Tianjin Port in Tianjin, China. The blasts happened in a warehouse designed to store dangerous and toxic chemicals. The blasts were caused by the ignition of hazardous materials improperly or illegally stored at the site. The fire spread and ignited other chemicals, which finally led to two blasts. These two blasts caused 165 deaths and the direct economic loss of 6.87 billion yuan (about 1.1 billion U.S. dollars).

A wide range of organizations with jurisdictional backgrounds participated in the disaster response. By jurisdictions, national, provincial, and local (mainly municipal) organizations engaged in disaster response. The Binhai government immediately mobilized local organizations to respond. As the disastrous situation deteriorated and overwhelmed the capacity of the local organizations, the organizational network expanded to include provincial and national organizations. The Tianjin government set up a provincial emergency management headquarters (Tianjin EMH) to coordinate provincial organizations. At the national level, President Xi Jinping and Premier Li Keqiang urged an all-out effort to save people. Upon hearing these instructions, the State Council sent a team of representatives from several ministries based on the needs of the affected area.

At each level, the organizational network included public organizations, public institutions, state-owned enterprises, nonprofits, and private actors. For example, national ministries, such as the National Health Commission, the National Fire and Rescue Department, and the National Work Safety Administration sent professional rescue teams to assist with rescue operations. Some state-owned enterprises, such as China Mobile, State Grid Tianjin Electric Power Company, and Aviation Industry Corporation of China, maintained lines of communication and provided energy resources. National nonprofits, such as the Red Cross Society of China and the China Soong Ching Ling Foundation, raised money and provided medical services in the disaster response. At the provincial and local levels, the disaster response operation included organizations with different sectoral backgrounds. Thus, the Tianjin Port blast response involved numerous organizations and rescue teams from different sectors and jurisdictions.

\section{Data and Methods}

4.1. Data Collection. For the data collection, we used mixed methods to identify the participating organizations and their relationships in the Tianjin Port blast. First, the network data were collected through an iterative content analysis of online texts: local newspapers and organizational websites. We selected local newspapers and websites as the primary data source because of the deficiencies in traditional interviews and surveys. In disaster response, organizational networks are constructed over time, and individual actors have a limited understanding of their network structure. Traditional interviews and surveys that rely on memory may not provide objective information about the network structure and can create recollection bias or errors [59, 60]. Local newspaper articles record events as they occur. Organizations' websites carry information about the organizations' activities. Thus, local newspapers and organizations' websites provided relatively objective information of the event as it occurred and may have helped us avoid the potential errors and biases to which traditional research instruments are prone $[59,60]$.

In terms of local newspapers, we conducted a content analysis of articles published in Tianjin Daily within the three weeks following the disaster (from August 13 to September 2, 2015). To screen for relevant news articles, we looked through the newspaper daily. In terms of organizations' websites, we used emergency operations plans (EOPs) to identify potential participating organizations. EOPs clearly define the roles and responsibilities of key organizations [32]. We selected relevant EOPs at the national, provincial, and municipal levels to identify key organizations. Then, we looked through their official websites to trace the actions of the participating organizations (Table 1). The observation period was from August 13 through September 3, 2015. As this study focuses on the organizational network, we only included articles that described joint actions taken by organizations or organizational 
TABLE 1: Sources of some key organizational websites and newspapers.

\begin{tabular}{l}
\hline Jurisdiction \\
$\begin{array}{l}\text { The State Council, the National Wobsites of organizations } \\
\text { Ministry of Public Safety, the Ministry of Transport, and the Red Cross Society of China }\end{array}$ \\
$\begin{array}{l}\text { Trovincial } \\
\text { websites } \\
\text { The Tianjin Government, the Tianjin Health and Birth Planning Committee, the Tianjin Work Safety Administration, } \\
\text { the Tianjin Public Safety Department, the Tianjin Civil Affairs Department, the Tianjin Transport Committee, the } \\
\text { Tianjin Justice Department, and the Tianjin Health and Family Planning Committee }\end{array}$ \\
The Binhai Government \\
Tianjin Daily
\end{tabular}

representatives and excluded articles that shared emotional stories about individual victims and affected families. After carefully reading the prospective texts, we identified 153 articles as relevant.

We conducted a content analysis of the selected articles to identify the names of the participating organizations based on their entry into the disaster response operation. We also collected information on organizations' sectoral and jurisdictional attributes. Sectoral attributes were classified into five categories: public organizations, privates, nonprofits, public institutions, and state-owned enterprises. We classified the jurisdictional attributes into three categories: national, provincial, and local (municipal and county). The jurisdictions of public organizations, public institutions, and state-owned enterprises were judged based on each organization's level of jurisdictional authority. The jurisdictions of nonprofits and private companies were evaluated based on their geographic operational areas, which roughly correspond to the geographic boundaries of public jurisdictions [61]. We verified sectoral and jurisdictional attributes by checking the organizations' websites and their self-designated status from their mission statements or legal authority. For those organizations that do not have official websites, we used Baidu Baike (a Chinese search engine similar to Google) to confirm their sectoral and jurisdictional attributes.

Finally, ties and their directions were defined if an article reported the actual occurrence of the sharing of information, resources, and ideas. For example, an article stated that "a local organization sent request resources from the provincial organization, and the provincial organization sends requested resources to the local organization." The research coded an outgoing tie from the provincial public organization to the local organization. Likewise, reciprocal dyad links were coded between two organizations in the article "the Tianjin government and State Council's taskforce jointly making strategic decisions on rescuing."

Field visits and interviews were conducted from September 27 to September 28. We interviewed two local emergency managers (including municipal level) from the local emergency management office because they operated on the blast site and could provide details that could not be presented by secondary data. Another two provincial government officers from the housing department and public complaints and proposal administration were also interviewed because of their roles in the initial and recovery stages. We asked them questions about how they gathered information, the roles they played in the disaster response, and with whom and how they collaborated.
The data collection process identified 357 organizations with 677 directed ties (Table 2). For the network analysis, we transformed the data into a $357 \times 357$ directed asymmetric adjacency matrix. The value of each row of columns represents relationships that each organization established initially with the other 356 organizations in the given network. The identified relationships among organizations are directional, and hence network data are asymmetric in their structure. For example, organization A established relationships with organization B initially; it is not always true that B would indicate A as its working partner (see Figure 1). In this case, the value of the element in the adjacency matrix that presents a tie from $A$ to $B$ is 1 , while the value of the element in the adjacency matrix that presents a tie from $B$ to $\mathrm{A}$ is 0 .

4.2. Methods and Modelling. In this study, ERGMs were the primary method for testing the hypotheses about organizational partnering strategies. The underlying assumption of ERGMs is that relationships between actors are not independent of each other but are influenced by potential relationships between other individuals in the group [62]. An ERGM is conceptually similar to a logistic regression analysis, which can provide statistical analysis and theory testing. In ERGMs, the dependent variable is the existence of a tie between a pair of actors, and independent variables are node attributes, link variables, and the whole network structure. Similar to logistic regression analysis, the estimated coefficient indicates the correspondence between a one-unit change in the predictor and the log odds of a tie existing.

In this study, we constructed three models to test our hypotheses. Model I is a null model to catch the propensity for the formation of a network tie without considering other effects.

In model II, we examined two endogenous partnering strategies: the bonding structure strategy and the power concentration strategy. First, to examine the bonding structure strategy and test Hypotheses 1 and 2, we used mutual ties and geometrically weighted edgewise shared partner (GWESP) to measure reciprocity and transitive clustering, respectively. To test Hypothesis 1, the number of mutual ties was calculated to capture the tendency of organizations to build reciprocal relationships. When measuring the transitive clustering effects and testing Hypothesis 2, we selected GWESP statistics rather than triangles because we encountered a model degenerating problem with the simple triangles. GWESP accounts for triangles to form ties 
TABle 2: Number distribution of interacting organizations by level of jurisdiction and source of funding.

\begin{tabular}{lcccc}
\hline & National & Provincial & Local & Total \\
\hline Public & 34 & 72 & 62 & 168 \\
Public institution & 9 & 62 & 2 & 73 \\
State-owned & 10 & 18 & 1 & 29 \\
Nonprofit & 14 & 21 & 4 & 39 \\
Private & 34 & 9 & 5 & 48 \\
Total & 101 & 182 & 74 & 357 \\
\hline
\end{tabular}

with many shared partners as an extension of transitivity, which helps foster trust and reliability in a network. Secondly, to examine the power concentration strategy and test Hypothesis 3 , we used the geometrically weighted in-degree distribution (gwidegree). Gwidegree captures the tendency of organizations to connect with a popular organization. It represents a network that prefers for the connection between a large number of low degree actors and a smaller number of high degree actors, which is similar to the power concentration strategy.

In model III, we examined the impact of homophily and organizational attributes on the formation of a collaborative relationship. First, we examined the homophily strategy and tested Hypotheses 4 and 5. To test the homophily hypotheses, this study constructed "sectoral homophily" and "jurisdictional homophily." These measure whether two organizations within the same sector or jurisdiction are more likely to collaborate. In this study, sector attributes include "public organizations," "state-owned enterprises," "public institutions," "nonprofits," and "privates." Jurisdiction attributes include "national," "provincial," and "local." Secondly, we examined the organizational attribute strategy and tested Hypotheses 6 and 7. The organizational attribute strategy measures which types of organizations are most active in networks. To test Hypotheses 6 and 7, we measured the differences in activity levels across organizational sectors or jurisdictions compared to base categories. The base category for the sector was set to the public organization, and the base category for the jurisdiction was set to local.

Recent advances in the Markov Chain Monte Carlo Maximum Likelihood Estimation (MCMC MLE) technique allow us to estimates parameter values [63]. MCMCMLE is based on refining approximate parameter estimates by comparing the observed graph against the distribution of random graphs generated by a stochastic simulation using the approximate parameter values. If the parameter estimates never converge, the model is likely to be degenerate. Convergence is assessed on the t-ration of parameter estimates and tells us how close the simulated networks are observed network. In this study, we require all parameter estimates t-ration to be less than 0.1 , which means the simulated model networks are not significantly different from the observed data. This is the convergence standard suggested by Robins et al. [62] and has been used in other studies as a criterion for model convergence [16, 45, 47].

To further determine the quality of the final model (Model III), randomly generated networks were compared to the observed network by assessing the goodness of fit of the ERGMs in plots. We chose the indegree statistic, outdegree statistic, edgewise shared partner, and geodesic distance, because these standard measures were directly linked to our research goals [64]. An ERGM modelling package, $\mathrm{R}$ package Statnet, was used to conduct the modelling and data analysis processes.

\section{Results and Findings}

5.1. Descriptive Statistics of Network. Before discussing ERGM results, we provide descriptive statistics to facilitate the understanding of the Tianjin Port blast response network. Table 3 describes the overall characteristics of the network that we investigated. The average degree counts the number of links that actors had with other actors. The average degree (1.89) indicates that on average, an actor interacted with approximately two organizations. Distance indicates the average number of links in the shortest path connecting any two actors across the network [65]. According to this definition, we considered all connected pairs of actors across the whole network when we calculated the average distance. Meanwhile, since we treat the whole network as asymmetric, we considered directionality when we calculated the average distance with Ucinet. The average distance measure (5.09) indicates that all organizations were approximately 5.1 steps away from each other in the Tianjin Port blast response network. Reciprocity describes the proportion of mutual ties in a directed network. The reciprocity measure (0.09) indicates that, among all relationships, 9\% were reciprocal. Transitivity measures the probability to form a closed-network structure. The transitivity measure (0.09) indicates that, among all relationships, $9 \%$ were tightly clustered triads.

Figures 2 and 3 map the Tianjin Port blast response network. Different colors represent organizational attributes, links represent the relationships among the organizations, and arrows represent the direction of the relationships. The visualization of the network shows that organizations tended to cluster with others that had similar sectoral or jurisdictional attributes. For example, in terms of sectoral attributes, public organizations (red) clustered with other public organizations (red). In terms of jurisdictional attributes, local organizations (red) clustered with other local organizations and national organizations (blue) clustered with other national organizations (blue).

5.2. ERGM Analysis. Table 4 summarizes the ERGM results. The numbers are estimated parameter (EST) values and standard errors (SEs). Estimated parameters show straightforward information about the likelihood of different partnering strategies being observed in a given set of network data. The direction and significance of coefficients indicate the conditional logit of tie formation: increasing and decreasing probabilities of relationships among actors within the organizational network in disaster response. The Akaike information criterion and the Bayesian information criterion drove the selection criterion. 
Table 3: Descriptive statistics of the Tianjin Port blast response network structure.

\begin{tabular}{lccccc}
\hline Node & Links & $\begin{array}{c}\text { Average } \\
\text { degree }\end{array}$ & $\begin{array}{c}\text { Average } \\
\text { distance }\end{array}$ & Reciprocity & Transitivity \\
\hline 357 & 677 & 1.89 & 5.09 & 0.09 & 0.09 \\
\hline
\end{tabular}

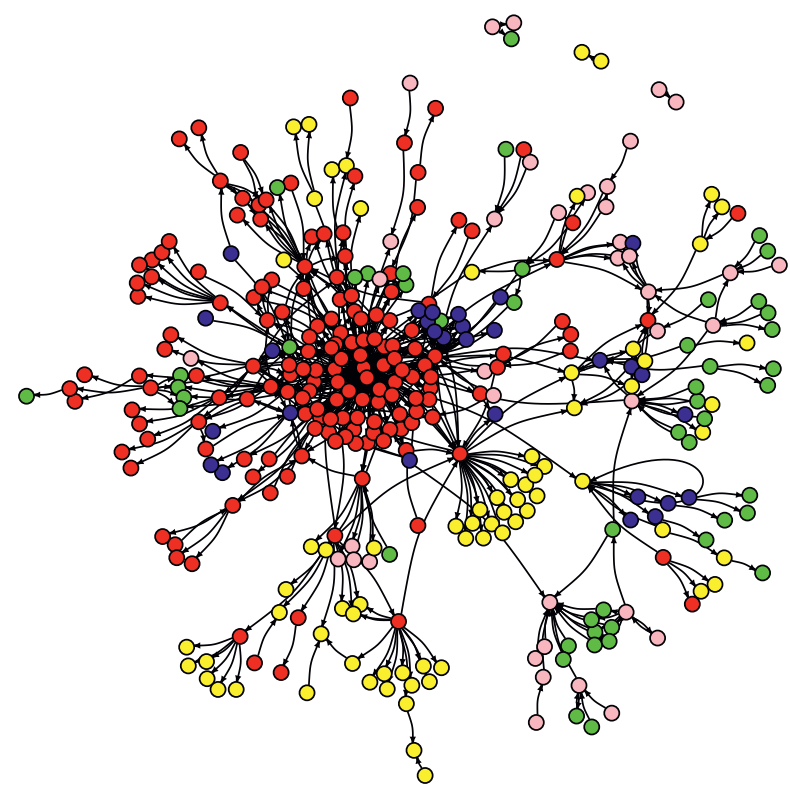

Figure 2: The Tianjin Port blast response network by funding source. Red $=$ public, yellow $=$ public institution, blue $=$ stateowned, pink $=$ nonprofit, green $=$ private .

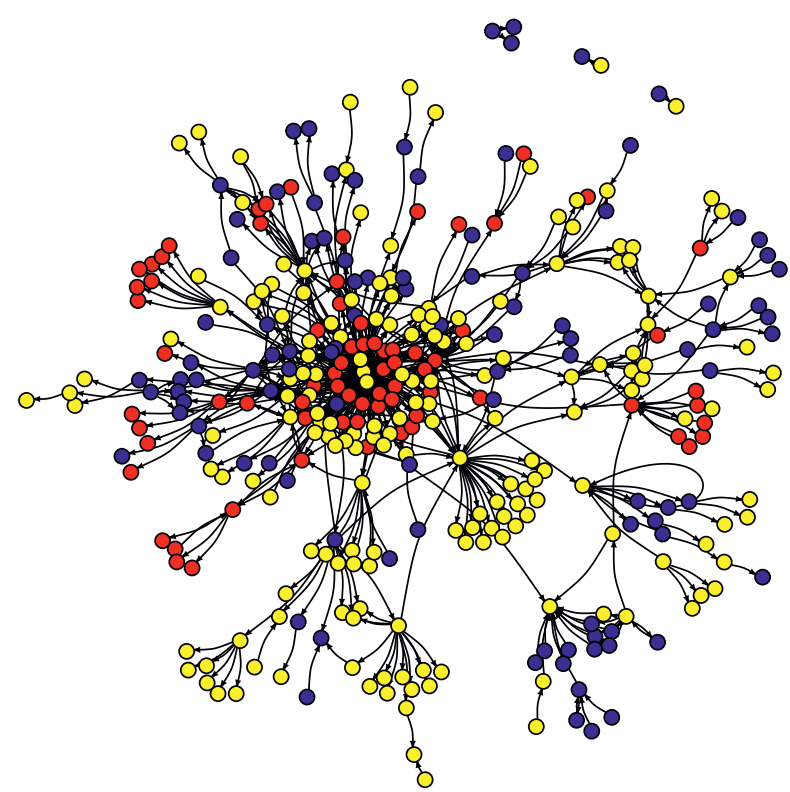

Figure 3: The Tianjin Port blast response network by jurisdiction. Red $=$ local, yellow $=$ provincial, blue $=$ national .

The first column of the table reports the estimates of the baseline model (Model I), which only catches the propensity for the formation of a network tie without considering other factors. The coefficient $(-5.230)$ indicates that the propensity for the creation of a network tie is $5.3 \%$.

Model II estimates two endogenous partnering strategies. The results in Table 4 reveal that the "reciprocity" and "transitive clustering" associated with basic social bonding structures are preferred by organizations in disaster operational networks. The results support Hypotheses 1 and 2 . More specifically, organizations are 2.2 times more likely to form reverse ties if there are existing ties. Organizations with shared partners are 18.3 times more likely to have direct ties. These inferences hold even when considering the effects of homophily and the effect of actor attributes in Model III. "Reciprocity" and "transitive clustering" imply that emergency response organizations tend to facilitate mutual benefits and work together in a triadic structure, which ensures the maintenance of actors' commitment to collective solutions and reduces the risk of defection [46]. In the disaster context, emergency response organizations need to acquire resources and information quickly. Establishing and maintaining relationships with unfamiliar organizations may be too risky for them. Therefore, emergency response organizations forge tightly directed and closed relationships in disaster response. In these structures, organizations can manage and evaluate the quality of relationships to reduce risks and monitor and support their partners' decisions as they cope with relevant tasks.

A positive coefficient of "gwidegree" may suggest that the emergence of "star" networks is also more likely to occur. This finding is consistent with our speculation on the preference to establish relationships with popular organizations. When viewed on the whole network level, a "star" represents a structure in which one central actor is connected with other actors to provide the most efficient transmission and distribution of information [66]. In disaster response, it is more likely that resources and information will be unevenly diffused among several network actors, leading to a situation in which most organizations will rely entirely on a small number of central actors. Table 5 shows the top 5 organizations by indegree centrality. The Tianjin Government, the Binhai Government, Tianjin Chinese Communist Party (CCP) Committee, and Tianjin $\mathrm{EMH}$ were the key network administrators for coordinating resources and information. Connecting with these network administrators provided actors with timely information and the resources they needed. The Tianjin Red Cross Society also made resources and information available and connecting with them delivered the most efficient structure for transmission.

In Model III, the positive coefficients of sectoral and jurisdictional homophily mean that organizations with the same characteristics are more likely to forge network ties. Emergency organizations are 2.0 times more likely to form relationships if they share the same sector and 1.2 times more likely to develop relationships if they share the same jurisdiction. The portion of ties among the same sector is 63.07 percent (423 out of 677), including 375 links among public organizations, 17 links among public institutions, 6 links among state-owned enterprises, 25 links among nonprofits, and 4 links are among private companies. The 
TABLE 4: Estimation results: estimates and standard errors.

\begin{tabular}{|c|c|c|c|c|c|c|}
\hline & \multicolumn{2}{|c|}{ Model I } & \multicolumn{2}{|c|}{ Model II } & \multicolumn{2}{|c|}{ Model III } \\
\hline & EST & SE & EST & SE & EST & SE \\
\hline Edges & $-5.230^{\mathrm{a}}$ & 0.039 & $-6.232^{\mathrm{a}}$ & 0.048 & $-6.785^{\mathrm{a}}$ & 0.128 \\
\hline H1: reciprocity & - & - & $0.075^{\mathrm{a}}$ & 0.085 & $1.274^{\mathrm{a}}$ & 0.115 \\
\hline $\mathrm{H} 2$ : transitive clustering & - & - & $2.93^{\mathrm{a}}$ & 0.049 & $2.487^{\mathrm{a}}$ & 0.089 \\
\hline H3: preferential attachment & - & - & $0.965^{\mathrm{a}}$ & 0.237 & $1.396^{\mathrm{a}}$ & 0.257 \\
\hline H4: sectoral homophily & - & - & - & - & $0.698^{\mathrm{a}}$ & 0.054 \\
\hline H5: jurisdictional homophily & - & - & - & - & $0.203^{\mathrm{a}}$ & 0.046 \\
\hline H6: sector (base = public) & - & - & - & - & - & - \\
\hline Public institution & - & - & - & - & $-0.3711^{\mathrm{a}}$ & 0.035 \\
\hline State-owned & - & - & - & - & $0.200^{\mathrm{a}}$ & 0.051 \\
\hline Nonprofit & - & - & - & - & $0.180^{\mathrm{a}}$ & 0.044 \\
\hline Private & - & - & - & - & $-0.189^{\mathrm{a}}$ & 0.050 \\
\hline H7: jurisdiction $($ base $=$ local $)$ & - & - & - & - & - & - \\
\hline Provincial & - & - & - & - & $0.118^{\mathrm{b}}$ & 0.037 \\
\hline National & - & - & - & - & $0.160^{\mathrm{a}}$ & 0.042 \\
\hline Akaike information criterion (AIC) & 8441 & - & 7158 & - & 6913 & - \\
\hline Bayesian information criterion (BIC) & 8450 & - & 7197 & - & 7030 & - \\
\hline
\end{tabular}

All statistics converged with a $t$-statistic $<0.1$ with a minimum of 1000 iterations for each model. ${ }^{a}$ Significance at the $0.1 \%$ level, ${ }^{b}$ significance at the $1 \%$ level, and ${ }^{\mathrm{c}}$ significance at the $5 \%$ level.

TABle 5: Indegree centrality ranking (top 5 scorers) in Tianjin Port blast response network.

\begin{tabular}{lc}
\hline Organization & Value \\
\hline Tianjin Government & 26 \\
Binhai Government & 24 \\
Tianjin Chinese Communist Party Committee & 22 \\
Tianjin Red Cross Society & 14 \\
Tianjin EMH & 13 \\
\hline
\end{tabular}

portion of ties among the same jurisdiction is 62.63 percent (421 out of 677), including 92 links among national organizations, 306 links among provincial organizations, and 29 among local organizations.

The confirmation of Hypotheses 4 and 5 generally suggests organizations employ the homophily strategy to secure credible commitments among potential cooperators. As discussed in Section 3, organizational similarities may help reduce the risk and uncertainty of collaborations. Within the same sectors and jurisdictions, organizations are more likely to enhance trust and maintain strong goal commitment through shared operational cognitions and previously shared authority $[6,56]$.

In Model III, the strong negative coefficients of public institutions and private companies suggest that they are more likely to forge links with public organizations. The strong positive coefficients of state-owned enterprises and nonprofits indicate that they are unlikely to forge network links with public organizations, which is inconsistent with Hypothesis 6. An effective response requires cross-sectoral collaboration. Insufficient cross-sectoral collaboration can prevent opportunities for new resources and information and may lead to a failure in disaster response. For example, poor information sharing between privates and state-owned enterprises and public organizations led to the Tianjin Fire Department having no idea that large amounts of chemicals were stored in the warehouse and would trigger explosions.
As a result, firefighters did not retreat quickly enough, and many of them were killed by the explosions.

The positive coefficients of provincial and national organizations suggest that local organizations tend to establish and maintain relationships with provincial organizations, while national organizations do not. The results do support Hypothesis 7.

Within a disaster context, the reasons differ for local and national organizations to collaborate with provincial organizations. Local organizations need to acquire information and resources from provincial organizations. For example, the Binhai Emergency Management Office received an initial fire report from the Tianjin Provincial Emergency Office and the Tianjin Firefight Department. Local organizations need to communicate with provincial organizations to provide timely feedback when they execute tasks.

National organizations rely on provincial organizations to translate knowledge from local practice into a more technical and standardized feed-forward format for the national level. However, in our interviews, we found that national and provincial organizations were not well-coordinated at the initial stage of disaster response. National ministries, such as the Work Safety Administration and the Environmental Protection Administration, set up their own headquarters on the frontline. These headquarters commanded their own rescue efforts and worked alone without coordination with provincial organizations. A unified command center did not oversee the coordination of the rescue teams and resources at national and provincial levels, which explains why the coefficient of the national organization is not statistically significant.

Figure 4 shows how well the model captures the data structure. The four graphs present model diagnostics that compare the estimated network statistics with a large number of the simulated networks. In each graph, the vertical axis is relative frequency. The black ties indicate the observed statistics in the actual network, and the box plot 


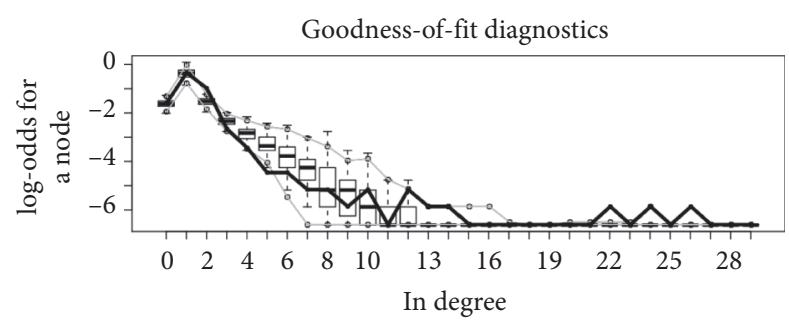

(a)

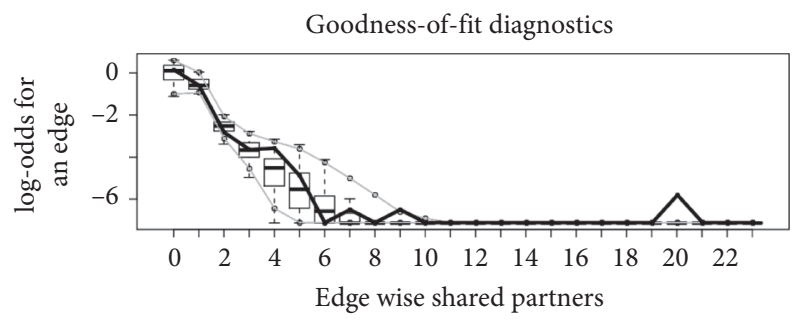

(c)

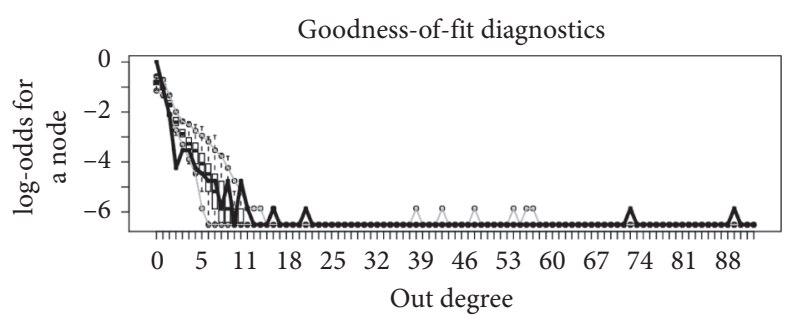

(b)

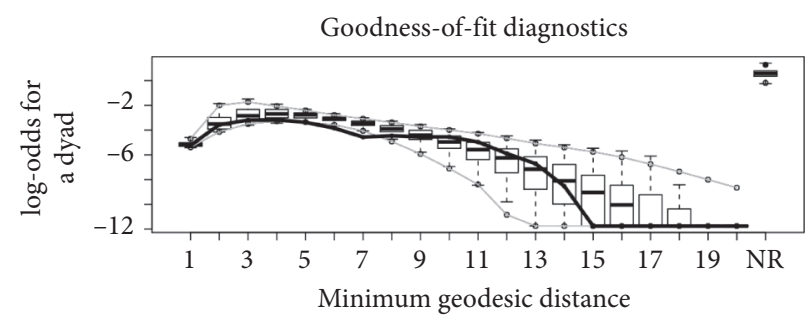

(d)

FIGURE 4: Four graphs for model III diagnostics.

represents each statistic of the simulated network. The graphs show that the estimated statistics of indegree, edgewised shared partners, and minimum geodesic distance are more similar to the simulated network statistics. In contrast, the estimated network statistics of outdegree are less similar to the simulated network statistics. Overall, the observed distributions fall with quantile curves for most of the range and correctly capture the shape of the distribution of the original network, which indicates that the model generated networks with characteristics similar to the observed network.

\section{Conclusion}

Organizational networks have become recognized as a dominant mechanism for addressing emergencies and disasters. Despite such growth, we still know little about partnering strategies of organizational networks in disaster response, especially in the centralized political context. In this study, we used ERGMs to examine organizational partnering strategies and to identify the characteristics of potential partners in disaster response. This study found that organizations prefer three different partnering strategies.

First, organizations prefer the bonding structure strategy to ensure goal commitment and reduce the risk of defection. This research finding is consistent with that of the most previous studies [16, 47]. In disaster response, organizations prefer to form the type of "reciprocity" and "transitive clustering" relationships that are associated with the basic social bonding structure. These two basic network configurations enhance trust and goal commitments among network actors and thus reduce the risk and uncertainty of defection [50]. In disaster response, organizations need to operate at different scales of authority and capacity simultaneously and under high levels of collective stress and uncertainty. Thus, actors may be better served by participating in a densely clustered network that ensures commitment to collective solutions [46].

Second, organizations also prefer the power concertation strategy to secure information. This research finding contradicts the previous findings in the emergency management literature. Yeo [16] found that in broader management networks, organizations are unlikely to build relationships with popular actors perhaps because greater reliance on a few actors could hinder timely response. The network literature generally suggests that organizations can still benefit new information and resources without creating ties to others. In other words, organizations can explore an extensive set of possible strategies with others simply by being connected to a popular organization that can efficiently process and distribute multiple sets of information and actions [47]. In disaster response, organizations need to act quickly and effectively in response to urgent needs. It is impractical for an organization to maintain a large number of ties to get information and resources. Rather, connecting to popular organizations is an efficient way for them to get the skills and resources they need. In a centralized political context, resources and information may not be dispersed but be concentrated on key actors. Through establishing relationships with these popular organizations, organizations can get timely information and network can improve their efficiency.

Third, our analysis also confirms the homophily strategy. Organizations from the same sector or jurisdiction have a strong preference to forge ties with each other. As discussed in Section 2, similarities between organizations can enhance the trust and shared operation cognitions that may forge collaboration in disaster response $[6,56]$.

Forth, our analysis rejects the organizational attributes hypothesis. Some participating organizations are less likely to prefer creating a tie with public organizations and provincial organizations as a strategy to obtain information. The 
positive coefficients of nonprofits in our study showed that these organizations are less likely to collaborate with public organizations. This may be explained by contextual backgrounds. Different from the western context, most nonprofits exist on a small scale and have limited financial and human resources. Thus, public organizations may be reluctant to work with nonprofits because they doubt nonprofits' motivations and abilities in disaster response. In terms of jurisdictional attributes, we found that national organizations are unwilling to collaborate with provincial organizations. This may attribute to the conflict between the vertical management structure and horizontal management structure. In China, government agencies are ordered by the parallel jurisdictional government and instructed by higher jurisdictional supervisors. For example, the Environmental Protection Department of Tianjin is under the jurisdiction of the Tianjin Government and also instructed by its national supervisor, the Ministry of Environmental Protection. In our case, some national ministries also sent taskforces or representative teams and set up their headquarters. This dualmanagement structure created conflicts in commanding and further prevented organizational coordination.

This study suggests several recommendations to enhance organizational collaboration within disaster response networks, especially among public organizations with different jurisdictions and between them and other types of organizations. First, in terms of sectoral attributes, it is critical to encourage cross-sector collaborations between public organizations and nonprofits. For nonprofits, working with public organizations may help them obtain the resources they need. More importantly, working with public organizations may help them earn trust and recognition, thereby improving their social status and legitimacy. To achieve wellcoordinated actions between public organizations and nonprofits, on one hand, key nonprofits can be identified before a disaster and included in the core network through planning and training exercises. Moreover, nonprofits need to self-organize to provide a single point for network administrators to reduce coordination costs. Second, in terms of jurisdictions, national public organizations need to develop their relationships with provincial organizations to be able to gather local information and coordinate collective actions better. For coordination to be successful, there must exist a carefully crafted, clear, and unambiguous set of relationships delineated for each element of the system, with clear lines of authority developed to link the various pieces together in a rational manner. Thus, responsibilities between the provincial government and national ministries need to be further clarified in law.

This research has two limitations. First, the findings are highly dependent on the research context. Our research findings may be snapshots of disaster operation networks in China. To improve generalizability, this study could be replicated in other contexts. Second, it is important to remember that networks are not static, and thus the roles of the endogenous and exogenous effects may change over time. Therefore, further studies could conduct longitudinal analyses of network formations and evolutions using the temporal exponential random graph model.

\section{Data Availability}

The data are not freely available, and access to data is restricted.

\section{Conflicts of Interest}

The authors declare that there are no conflicts of interest.

\section{Acknowledgments}

This research was funded by the National Natural Science Foundation of China (Grant no. 71921003), "Environmental Risk Management," and National Foundation for Social Science of China (Grant no. 17VZL018), "Prevention and Resolution of Major Risks."

\section{References}

[1] R. Agranoff and M. McGuire, "Big questions in public network management research," Journal of Public Administration Research and Theory, vol. 11, no. 3, pp. 295-326, 2001.

[2] K. R. Isett, I. A. Mergel, K. Leroux, P. A. Mischen, and R. K. Rethemeyer, "Networks in public administration scholarship: understanding where we are and where we need to go," Journal of Public Administration Research and Theory, vol. 21, no. Supplement 1, pp. i157-i173, 2011.

[3] C. Perrow, Normal Accidents: Living with High-Risk Systems, Basic Books, New York, NY, USA, 1984.

[4] B. A. Turner and N. F. Pidgeon, Man-made Disasters, Butterworth-Heinemann, Oxford, UK, 1997.

[5] F. Zhang, E. W. Welch, and Q. Miao, "Public organization adaptation to extreme events: mediating role of risk perception," Journal of Public Administration Research and Theory, vol. 28, no. 3, pp. 371-387, 2018.

[6] L. K. Comfort, "Crisis management in hindsight: cognition, communication, coordination, and control," Public Administration Review, vol. 67, pp. 189-197, 2007.

[7] C. Ansell and A. Gash, "Collaborative governance in theory and practice," Journal of Public Administration Research and Theory, vol. 18, pp. 543-571, 2008.

[8] L. J. O’Toole, "Treating networks seriously: practical and research-based agendas in public administration," Public Administration Review, vol. 57, pp. 45-51, 1997.

[9] W. L. Waugh Jr. and G. Streib, "Collaboration and leadership for effective emergency management," Public Administration Review, vol. 66, no. s1, pp. 131-140, 2006.

[10] N. Kapucu and V. Garayev, "Structure and network performance: horizontal and vertical networks in emergency management," Administration \& Society, vol. 48, no. 8, pp. 931-961, 2016.

[11] L. Hossain, J. Hamra, R. T. Wigand, and S. Carlsson, "Exponential random graph modeling of emergency collaboration networks," Knowledge-Based Systems, vol. 77, pp. 68-79, 2015.

[12] K. Kim, H. Y. Yoon, and K. Jung, "Resilience in risk communication networks: following the 2015 MERS response in South Korea," Journal of Contingencies and Crisis Management, vol. 25, no. 3, pp. 148-159, 2017.

[13] S. Uddin, J. Hamra, and L. Hossain, "Exploring communication networks to understand organizational crisis using exponential random graph models," Computational and 
Mathematical Organization Theory, vol. 19, no. 1, pp. 25-41, 2013.

[14] Ö. Bodin and D. Nohrstedt, "Formation and performance of collaborative disaster management networks: evidence from a Swedish wildfire response," Global Environmental Change, vol. 41, pp. 183-194, 2016.

[15] Ö. Bodin, D. Nohrstedt, J. Baird, R. Summers, and R. Plummer, "Working at the "speed of trust": pre-existing and emerging social ties in wildfire responder networks in Sweden and Canada," Regional Environmental Change, vol. 19, no. 8, pp. 2353-2364, 2019.

[16] J. Yeo, "Antecedents of border management network in El Paso, Texas: an exponential random graph model," Journal of Homeland Security and Emergency Management, vol. 15, 2018.

[17] T. A. B. Snijders, "Statistical models for social networks," Annual Review of Sociology, vol. 37, no. 1, pp. 131-153, 2011.

[18] L. K. Comfort and H. Zhang, "Operational networks: adaptation to extreme events in China," Risk Analysis, vol. 40, no. 5, pp. 981-1000, 2020.

[19] N. Kapucu, "Interorganizational coordination in complex environments of disasters: the evolution of intergovernmental disaster response systems," Journal of Homeland Security and Emergency Management, vol. 6, no. 1, 2009.

[20] S. E. Clarke and E. Chenoweth, "The politics of vulnerability: constructing local performance regimes for homeland security," Review of Policy Research, vol. 23, no. 1, pp. 95-114, 2006.

[21] L. K. Comfort, Shared Risk: Complex Systems in Seismic Response, Pergamon Press, Oxford, UK, 1999.

[22] L. K. Comfort and N. Kapucu, "Inter-organizational coordination in extreme events: the world trade center attacks, September 11, 2001," Natural Hazards, vol. 39, no. 2, pp. 309-327, 2006.

[23] D. P. Moynihan, "Combining structural forms in the search for policy tools: incident command systems in US. Crisis management," Governance, vol. 21, no. 2, pp. 205-229, 2008.

[24] E. H. Klijn and J. F. M. Koppenjan, "Public management and policy networks: foundations of a network approach to governance," Public Management, vol. 2, no. 2, pp. 135-158, 2000.

[25] K. G. Provan, A. Fish, and J. Sydow, "Interorganizational networks at the network level: a review of the empirical literature on whole networks," Journal of Management, vol. 33, no. 3, pp. 479-516, 2007.

[26] H. B. Milward and K. G. Provan, "Governing the hollow state," Journal of Public Administration Research and Theory, vol. 10, no. 2, pp. 359-380, 2000.

[27] R. A. W. Rhodes, "The new governance: governing without government," Political Studies, vol. 44, no. 4, pp. 652-667, 1996.

[28] K. G. Provan and R. H. Lemaire, "Core concepts and key ideas for understanding public sector organizational networks: using research to inform scholarship and practice," Public Administration Review, vol. 72, no. 5, pp. 638-648, 2012.

[29] D. F. Kettl, "The global revolution in public management: driving themes, missing links," Journal of Policy Analysis and Management, vol. 16, no. 3, pp. 446-462, 1997.

[30] C. R. Wise, "Organizing for homeland security after Katrina: is adaptive management what's missing?" Public Administration Review, vol. 66, no. 3, pp. 302-318, 2006.

[31] N. Kapucu and V. Garayev, "Designing, managing, and sustaining functionally collaborative emergency management networks," The American Review of Public Administration, vol. 43, no. 3, pp. 312-330, 2012.
[32] Q. Hu, C. C. Knox, and N. Kapucu, "What have we learned since September 11, 2001? A network study of the Boston Marathon Bombings response," Public Administration Review, vol. 74, no. 6, pp. 698-712, 2014.

[33] S. O. Choi and B.-T. Kim, "Power and cognitive accuracy in local emergency management networks," Public Administration Review, vol. 67, pp. 198-209, 2007.

[34] N. Kapucu and D. Fatih, "Measuring performance for collaborative public Management using network analysis methods and tools," Public Performance and Management Review, vol. 34, pp. 49-79, 2011.

[35] B. Nowell, T. Steelman, A.-L. K. Velez, and Z. Yang, "The structure of effective governance of disaster response networks: insights from the field," The American Review of Public Administration, vol. 48, no. 7, pp. 699-715, 2018.

[36] T. Vasavada, "Managing disaster networks in India," Public Management Review, vol. 15, no. 3, pp. 363-382, 2013.

[37] A. Abbasi and N. Kapucu, "A longitudinal study of evolving networks in response to natural disaster," Computational and Mathematical Organization Theory, vol. 22, no. 1, pp. 47-70, 2016.

[38] M. T. Heaney, "Multiplex networks and interest group influence reputation: an exponential random graph model," Social Networks, vol. 36, pp. 66-81, 2014.

[39] E. Ostrom and J. Walker, Trust and Reciprocity: Interdisciplinary Lessons for Experimental Research, Russell Sage Foundation, New York, NY, USA, 2003.

[40] T. A. Birkland, "Disasters, catastrophes, and policy failure in the homeland security Era," Review of Policy Research, vol. 26, no. 4, pp. 423-438, 2009.

[41] X. Lu and L. Xue, "Managing the unexpected: sense-making in the Chinese emergency management system," Public Administration, vol. 94, no. 2, pp. 414-429, 2016.

[42] H. Zhang, X. Zhang, L. Comfort, and M. Chen, "The emergence of an adaptive response network: the April 20, 2013 Lushan, China earthquake," Safety Science, vol. 90, pp. 14-23, 2016.

[43] H. Zhang, "What has China learnt from disasters? Evolution of the emergency management system after SARS, Southern Snowstorm, and wenchuan earthquake," Journal of Comparative Policy Analysis: Research and Practice, vol. 14, no. 3, pp. 234-244, 2012.

[44] P. Kenis and D. Knoke, "How organizational field networks shape interorganizational tie-formation rates," Academy of Management Review, vol. 27, no. 2, pp. 275-293, 2002.

[45] R. C. Feiock, I. W. In Won Lee, H. J. Hyung Jun Park, K.-H. Lee, and K.-H. Lee, "Collaboration networks among local elected officials: information, commitment, and risk aversion," Urban Affairs Review, vol. 46, no. 2, pp. 241-262, 2010.

[46] R. D. Putnam, "Bowling alone: America's declining social capital," Journal of Democracy, vol. 6, no. 1, pp. 65-78, 1995.

[47] Y. Lee, I. W. Lee, and R. C. Feiock, "Interorganizational collaboration networks in economic development policy: an exponential random graph model analysis *." Policy Studies Journal, vol. 40, no. 3, pp. 547-573, 2012.

[48] R. Berardo and J. T. Scholz, "Self-organizing policy networks: risk, partner selection, and cooperation in estuaries," American Journal of Political Science, vol. 54, no. 3, pp. 632-649, 2010.

[49] R. C. Feiock and J. Scholz, Self-Organizing Federalism: Collaborative Mechanisms to Mitigate Institutional Collective Action Dilemmas, Cambridge University Press, New York, NY, USA, 2010. 
[50] J. S. Coleman, "Social capital in the creation of human capital," American Journal of Sociology, vol. 94, pp. 95-120, 1988.

[51] K. Thurmaier and C. Wood, "Interlocal agreements as overlapping social networks: picket-fence regionalism in metropolitan Kansas city," Public Administration Review, vol. 62 , no. 5, pp. 585-598, 2002.

[52] R. C. Feoick, I. W. Lee, and H. J. Park, “Administrators' and elected officials' collaboration networks: selecting partners to reduce risk in economic development," Public Administration Review, vol. 72, pp. 58-68, 2012.

[53] M. Lubell, "Familiarity breeds trust: collective action in a policy domain," The Journal of Politics, vol. 69, no. 1, pp. 237-250, 2007.

[54] R. Gulati and M. Gargiulo, "Where do interorganizational networks come from?" American Journal of Sociology, vol. 104, no. 5, pp. 1439-1493, 1999.

[55] M. McPherson, L. Smith-Lovin, and J. M. Cook, "Birds of a feather: homophily in social networks," Annual Review of Sociology, vol. 27, no. 1, pp. 415-444, 2001.

[56] D. P. Moynihan, "The network governance of crisis response: case studies of incident command systems," Journal of Public Administration Research and Theory, vol. 19, no. 4, pp. 895915, 2009.

[57] J. Yeo and L. K. Comfort, "An expected event, but unprecedented damage: structure and gaps of the large-scale response coordination of the 2011 Thailand floods," Disaster Prevention and Management: An International Journal, vol. 26, no. 4, pp. 458-470, 2017.

[58] H. Zhang and M. Yin, "The emergent multiple organizational networks in disaster response: a case study on the ludian earthquake, August 3, 2014, China," Journal of Public Management, vol. 13, pp. 84-96, 2016, in Chinese.

[59] K. D. Kim and L. Hossain, "Policy network approach to coordinated disaster response," 2013, https://arxiv.org/abs/ 1312.3693 .

[60] J. Pfeffer and K. M. Carley, "Rapid modeling and analyzing networks extracted from pre-structured news articles," Computational and Mathematical Organization Theory, vol. 18, no. 3, pp. 280-299, 2012.

[61] L. K. Comfort, T. W. Haase, G. Ertan, and S. R. Scheinert, "The dynamics of change following extreme events: transition, scale, and adaptation in systems under stress," Administration and Society, vol. 52, 2019.

[62] G. Robins, T. Snijders, P. Wang, M. Handcock, and P. Pattison, "Recent developments in exponential random graph $(P *)$ models for social networks," Social Networks, vol. 29, no. 2, pp. 192-215, 2007.

[63] T. Snijders, "Markov chain Monte Carlo estimation of exponential random graph models," Journal of Social Structure, vol. 3, pp. 1-40, 2002.

[64] D. R. Hunter, S. M. Goodreau, and M. S. Handcock, "Goodness of fit of social network models," Journal of the American Statistical Association, vol. 103, no. 481, pp. 248258, 2008.

[65] A. Barabási, Linked: The New Science of Networks, Basic Books, New York, NY, USA, 2002.

[66] R. S. Burt, Brokerage and Closure: An Introduction to Social Capital, Oxford University Press, New York, NY, USA, 2005. 